\title{
How Stress and Fluoxetine Modulate Serotonin 2C Receptor Pre-mRNA Editing
}

\author{
Michael T. Englander, ${ }^{1,3}$ Stephanie C. Dulawa, ${ }^{2}$ Punita Bhansali, ${ }^{3}$ and Claudia Schmauss ${ }^{1,3}$ \\ ${ }^{1}$ Department of Psychiatry and ${ }^{2}$ Center for Neurobiology and Behavior, Columbia University College of Physicians and Surgeons, New York, New York, \\ 10032, and ${ }^{3}$ Department of Neuroscience, New York State Psychiatric Institute, New York, New York 10032
}

In two inbred strains of mice, C57BL/6 and 129Sv, the majority of forebrain neocortical pre-mRNA encoding the serotonin $2 \mathrm{C}\left(5-\mathrm{HT}_{2 \mathrm{C}}\right)$ receptor is altered by adenosine-to-inosine editing. As a result, $>60 \%$ of all mRNAs encode receptors with reduced constitutive and agonist-stimulated activity. However, in the BALB/c strain, a genetically distinct inbred strain with lower forebrain serotonin levels, spontaneously elevated anxiety, and increased stress reactivity, the majority of 5- $\mathrm{HT}_{2 \mathrm{C}}$ mRNA is nonedited and encodes receptors with the highest constitutive activity and the highest agonist affinity and potency. Neither acute stress (the forced swim test) nor chronic treatment with the serotonin-selective reuptake inhibitor fluoxetine elicit significant changes in 5- $\mathrm{HT}_{2 \mathrm{C}}$ pre-mRNA editing in C57BL/6 mice. In contrast, exposure of $B A L B / c$ mice to acute stress and chronic treatment of nonstressed $B A L B / c$ mice with fluoxetine elicit significant, site-specific increases in 5- $\mathrm{HT}_{2 \mathrm{C}}$ pre-mRNA editing that increase the pool of mRNA encoding receptors with reduced function. These changes in $5-\mathrm{HT}_{2 \mathrm{C}}$ pre-mRNA editing resemble those detected previously in the prefrontal cortex of subjects with major depression. However, when chronic fluoxetine treatment is combined with stress exposure of $\mathrm{BALB} / \mathrm{c}$ mice, these changes in $5-\mathrm{HT}_{2 \mathrm{C}}$ pre-mRNA $^{-\mathrm{m}_{\mathrm{N}}}$ editing are no longer detected. These findings illustrate that $5-\mathrm{HT}_{2 \mathrm{C}}$ pre-mRNA editing responses to stress and chronic fluoxetine are modulated by the genetic background, as well as the behavioral state of the animal. They suggest further that the changes in $5-\mathrm{HT}_{2 \mathrm{C}}$ pre-mRNA editing found in major depression reflect a previously unrecognized molecular response to stress that can be prevented by chronic antidepressant treatment.

Key words: serotonin $2 \mathrm{C}$ receptor; RNA editing; forebrain; inbred mouse strains; stress; antidepressants

\section{Introduction}

The $5-\mathrm{HT}_{2 \mathrm{C}}$ receptor is a $\mathrm{G}$-protein-coupled receptor whose premRNA is a substrate for base modification via hydrolytic deamination of adenosines to yield inosines (Burns et al., 1997). Five adenosines (named A, B, C', C, and D editing sites), located within a sequence encoding the putative second intracellular domain of the $5-\mathrm{HT}_{2 \mathrm{C}}$ receptor, can be converted to inosines. This editing can alter the coding potential of three triplet codons and allows for the generation of 24 different receptor isoforms. Fully edited transcripts and partially edited transcripts that include at least editing of the $\mathrm{C}^{\prime}$ site or the $\mathrm{C}^{\prime}$ and $\mathrm{C}$ sites differ from nonedited receptors in their reduced ability to activate G-protein. This is evident in their decreased agonist-independent constitutive receptor activity, which leads to secondary decreases in agonist affinity and potency (Niswender et al., 1999; Wang et al., 2000). Moreover, in mouse forebrain neocortex, sustained activation of $5-\mathrm{HT}_{2 \mathrm{~A} / 2 \mathrm{C}}$ receptors leads to significantly increased $\mathrm{C}^{\prime}$ site editing and results in increased expression of mRNA isoforms encoding receptors with reduced basal and agonist-stimulated

Received Sept. 20, 2004; revised Nov. 23, 2004; accepted Nov. 29, 2004.

This work was supported by National Institutes of Health Grant MH61906 (C.S.). We thank Dr. Rene Hen (Columbia University) for his thoughtful input during the course of the study.

Correspondence should be addressed to Dr. Claudia Schmauss, Department of Psychiatry, Columbia University, Box 42, 1051 Riverside Drive, New York, NY 10032. E-mail: schmauss@neuron.cpmc.columbia.edu. DOI:10.1523/JNEUROSCI.3895-04.2005

Copyright $\odot 2005$ Society for Neuroscience $\quad$ 0270-6474/05/250648-04\$15.00/0 activity. Conversely, depletion of serotonin decreases $C^{\prime}$ - and $\mathrm{C}$-site editing and increases the pool of mRNA encoding receptor isoforms with the highest constitutive activity and the highest affinity for serotonin (Gurevich et al., 2002b). Hence, 5- $\mathrm{HT}_{2 \mathrm{C}}$ pre-mRNA editing is regulated by the cognate neurotransmitter itself and thus serves as a mechanism to maintain normal response properties of $5-\mathrm{HT}_{2 \mathrm{C}}$ receptors during periods of sustained changes in synaptic input.

In the prefrontal cortex (PFC) of suicide victims with a history of major depression, site-specific alterations in $5-\mathrm{HT}_{2 \mathrm{C}}$ premRNA editing lead to significantly increased expression of $5-\mathrm{HT}_{2 \mathrm{C}}$ mRNA isoforms encoding receptors with decreased basal activity and decreased agonist affinity and potency, and they are not a consequence of antidepressant treatment (Gurevich et al., 2002a). Depression, however, is thought to be associated with lower serotonin-mediated neurotransmission in the PFC (Nemeroff and Owens, 2002), suggesting that the serotonin-mediated regulation of $5-\mathrm{HT}_{2 \mathrm{C}}$ pre-mRNA editing is altered in depression.

Here, we test the hypothesis that a major psychopathological feature of depression, namely increased stress reactivity, is also a powerful determinant of $5-\mathrm{HT}_{2 \mathrm{C}}$ pre-mRNA editing and its regulation by serotonin. Because endogenous differences in the responses of serotonergic transmission to stressors could provide a basis for understanding the physiological differences between normal and depressed brains, we examined editing responses to stress in two genetically different inbred strains of mice, C57BL/6 
and $\mathrm{BALB} / \mathrm{c}$, which differ from one another in three important ways. (1) Compared with the C57BL/6 strain, BALB/c mice have approximately twofold lower levels of serotonin in the forebrain. This is attributable to a single-nucleotide polymorphism at codon 1473 (CGC encoding Arg) of the gene encoding tryptophan hydroxylase 2 (the major rate-limiting enzyme of brain 5-HT synthesis) that leads to a decreased catalytic activity of the enzyme (Zhang et al., 2004). (2) Compared with the generally nonanxious C57BL/6 strain, BALB/c mice exhibit spontaneously elevated anxiety and increased stress reactivity (Belzung and Griebel, 2001; Tang et al., 2002; Dulawa et al., 2004). (3) In behavioral paradigms of "learned helpnessness" (a model of depression), BALB/c mice, but not C57BL/6 mice, were found to be responsive to chronic (but not acute) treatment with the antidepressant drug fluoxetine (Dulawa et al., 2004). Thus, in these different inbred strains of mice, common genetic factors influence variations in spontaneous anxiety, stress reactivity, and responses to antidepressant drugs. Comparative studies on these mice can therefore illuminate the role of the genetic contribution to the modulation of $5-\mathrm{HT}_{2 \mathrm{C}}$ pre-mRNA editing responses to stress and chronic fluoxetine treatment.

We show here that, compared with C57BL/6 and 129Sv mice, $\mathrm{BALB} / \mathrm{c}$ mice exhibit a profoundly different basal forebrain neocortical $5-\mathrm{HT}_{2 \mathrm{C}}$ pre-mRNA editing pattern, and they exhibit stress-induced changes in $5-\mathrm{HT}_{2 \mathrm{C}}$ pre-mRNA editing resembling those detected in brains of depressed suicide victims. These changes, however, can be prevented by chronic fluoxetine treatment.

\section{Materials and Methods}

Analysis of 5- $H T_{2 C}$ pre-mRNA editing in mouse forebrain neocortex. All procedures involving animals were performed in accordance with the National Institutes of Health Guide for the Care and Use of Laboratory Animals and were approved by the Institutional Animal Care and Use Committee at Columbia University. Adult male 129Sv/EvTac, C57BL/6J, and BALB/cJ mice [age, postnatal day 60 (P60) to P90] were group housed in a standard animal care facility with a $12 \mathrm{~h}$ light/dark cycle during which they had ad libitum access to food and water.

Mice were killed by decapitation, and their brains were removed. Forebrain neocortical tissue was dissected for RNA extraction using guanidine/cesium chloride ultracentrifugation. Ten micrograms of total RNA was used to generate $5-\mathrm{HT}_{2 \mathrm{C}}$ cDNA by reverse transcription (RT)-PCR, as described previously (Gurevich et al., 2002b). PCR products were cloned into the plasmid vector pCRII (Invitrogen, Carlsbad, CA), and recombinant plasmids were introduced into bacteria. From each bacterial transformation that yielded $>300$ clones expressing recombinant plasmid DNA, 50-60 clones were picked randomly to process plasmid DNA for nucleotide sequencing using the dideoxy chain termination method in conjunction with $\left[{ }^{35} \mathrm{~S}\right] \mathrm{dATP}$ and the primer $5^{\prime}$-TATTTGTGCCCCGTCTG-3'.

Modified forced swim test. Adult male mice were subjected to a modified version of the forced swim test (FST) (Porsolt et al., 1977), as described previously by Dulawa et al. (2004). Briefly, they were placed for 6 min into plastic buckets ( $23 \mathrm{~cm}$ deep and $19 \mathrm{~cm}$ in diameter) filled with $23-25^{\circ} \mathrm{C}$ water. To establish a learned helpnessness paradigm that elicits behaviors that are modulated by chronic, but not acute, fluoxetine treatment (Dulawa et al., 2004), mice were reexposed to the forced swim test for $6 \mathrm{~min} 24 \mathrm{~h}$ after the first test. Twenty-four hours after the second test, mice were killed by rapid decapitation, their brains were removed, and forebrain neocortical tissues were dissected for RNA extraction.

Chronic treatment with fluoxetine. Fluoxetine (a generous gift from Eli Lilly, Indianapolis, IN) was delivered in the drinking water contained in opaque bottles, as described previously (Dulawa et al., 2004). Mice consumed $18 \mathrm{mg} \cdot \mathrm{kg}^{-1} \cdot \mathrm{d}^{-1}$ of fluoxetine for $24 \mathrm{~d}$, and they were either subjected to the forced swim test during the last $2 \mathrm{~d}$ of fluoxetine treatment or killed at the end of the treatment.
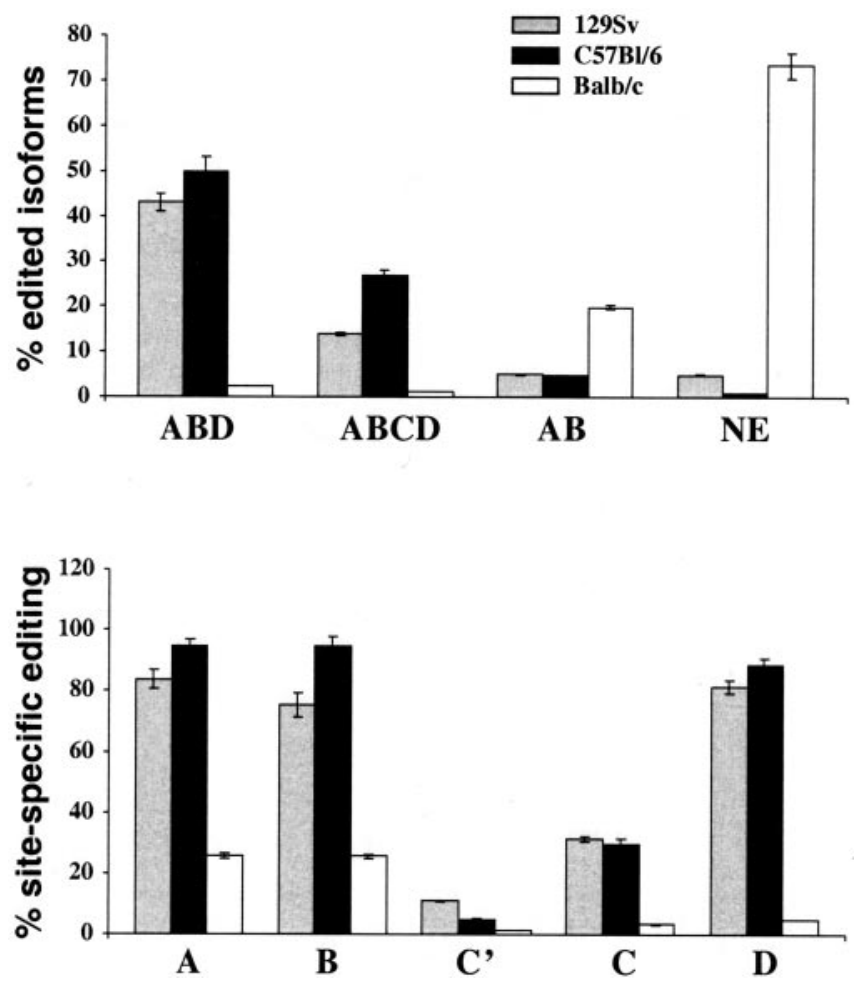

Figure 1. Percentages of major edited and nonedited (NE) $5-\mathrm{HT}_{2 \mathrm{C}} \mathrm{mRNA}$ isoforms (top) and percentages of site-specific editing (bottom) in the forebrain neocortex of $129 \mathrm{~Sv}, \mathrm{C57BL} / 6$, and $\mathrm{BALB} / \mathrm{c}$ mice. Adult male mice (P60-P70) were used in this study. Data represent means \pm SEM of determinations made in four (129Sv and $(57 \mathrm{BL} / 6)$ or five (BALB/C) animals. For each animal, a minimum of 50 sequences was obtained (totaling 213 sequences for 129Sv, 204 for C57BL/6, and 266 for BALB/C). The data obtained for $1295 v$ mice were reported previously (Gurevich et al., 2002a). The percentages of ABD- and ABCD-edited isoforms of $1295 \mathrm{v}$ and C57BL/6 mice did not significantly differ from each other, but they differed significantly from corresponding percentages determined for BALB/C mice (ANOVA; post hoc Tukey-Kramer multiple-comparison test; $p<0.001$ ). The percentages of nonedited and $A B$ edited $5-\mathrm{HT}_{2 C}$ mRNA are significantly higher in BALB/c mice compared with $1295 \mathrm{~V}$ and $\mathrm{C57BL} / 6$ mice ( $p<$ 0.001 and $p<0.05$, respectively).

\section{Results}

Basal 5- $\mathrm{HT}_{2 \mathrm{C}}$ pre-mRNA editing in different inbred strains of mice

We first compared the basal forebrain neocortical $5-\mathrm{HT}_{2 \mathrm{C}}$ premRNA editing pattern in three inbred strains of mice, $129 \mathrm{~Sv}$, $\mathrm{C} 57 \mathrm{BL} / 6$, and BALB/c. Figure 1 (top) shows that $129 \mathrm{~Sv}$ and $\mathrm{C} 57 \mathrm{BL} / 6$ mice share a very similar editing pattern of $5-\mathrm{HT}_{2 \mathrm{C}}$ mRNA. They express two major mRNA isoforms that are edited at the $\mathrm{ABD}$ and $\mathrm{ABCD}$ sites (the latter receptor isoform exhibits reduced constitutive activity and decreased agonist affinity and potency) and that together constitute $>60 \%$ of all mRNA isoforms. Nonedited mRNA or mRNA edited at $\mathrm{AB}$ sites were rarely detected in the two strains. BALB/c mice, however, express predominantly nonedited and $\mathrm{AB}$-edited $5-\mathrm{HT}_{2 \mathrm{C}} \mathrm{mRNAs}$. Both isoforms represent $93 \%$ of all $5-\mathrm{HT}_{2 \mathrm{C}}$ mRNA isoforms in these mice, and they encode receptors with the highest constitutive activity and the highest agonist affinity and potency. The different pattern of $5-\mathrm{HT}_{2 \mathrm{C}}$ mRNA isoform expression in BALB/c mice is a result of decreased editing at all five of the editing sites (one-way ANOVA; $p<0.0001$ ) compared with either $129 \mathrm{~Sv}$ or C57BL/6, and editing of $\mathrm{C}^{\prime}, \mathrm{C}$, and $\mathrm{D}$ sites is only rarely observed in these mice (Fig. 1, bottom).

One may speculate that the increased expression of most active $5-\mathrm{HT}_{2 \mathrm{C}}$ receptor isoforms in $\mathrm{BALB} / \mathrm{c}$ mice is an adaptive 
response to compensate for their lower serotonin levels by decreasing editing of $5-\mathrm{HT}_{2 \mathrm{C}}$ pre-mRNA to maintain normal responsiveness of the receptor to tonically released serotonin.

\section{The effect of stress on $5-\mathrm{HT}_{2 \mathrm{C}}$ pre- mRNA editing in $\mathrm{C} 57 \mathrm{BL} / 6$ and $\mathrm{BALB} / \mathrm{c}$ mice}

In the next series of experiments, drugnaive $\mathrm{C} 57 \mathrm{BL} / 6$ and $\mathrm{BALB} / \mathrm{c}$ mice were subjected to two consecutive FSTs (see Materials and Methods). Twenty-four hours after the second FST, mice were killed, and their forebrain $5-\mathrm{HT}_{2 \mathrm{C}}$ mRNA was isolated and sequenced. As illustrated in Figure 2, drug-naive C57BL/6 mice subjected to the FST do not exhibit significant changes in $5-\mathrm{HT}_{2 \mathrm{C}}$ pre-mRNA editing. The percentages of major edited isoforms as well as the percentages of A-, B-, C' -, C-, and D-site editing (calculated for all sequences analyzed) are very similar to those determined for nonstressed animals (Fig. $2 A, B)$. BALB/c mice, however, exhibit significantly decreased expression of the $A B$ sites-edited mRNA isoform, significantly increased expression of the ABCD sitesedited mRNA, decreased expression of nonedited mRNA, and significantly increased expression of mRNA edited at the ABD sites (Fig. 2C). These stress-induced changes in the percentages of major edited isoforms are attributable to significantly increased editing of A, B, C, and D sites of $5-\mathrm{HT}_{2 \mathrm{C}}$ pre-mRNA (Fig. $2 \mathrm{D}$ ), and they result in increased expression of $5-\mathrm{HT}_{2 \mathrm{C}}$ mRNA isoforms encoding receptors with reduced constitutive activity and decreased agonist affinity and potency.

\section{The effect of chronic fluoxetine on $5-\mathrm{HT}_{2 \mathrm{C}}$ pre-mRNA editing in $\mathrm{C} 57 \mathrm{BL} / 6$ and $\mathrm{BALB} / \mathrm{c}$ mice}

In the last series of experiments, mice were treated chronically with fluoxetine, a serotonin-selective reuptake blocker with antidepressant potency (see Materials and Methods). Chronic fluoxetine treatment of C57BL/6 mice led to only modest changes in $5-\mathrm{HT}_{2 \mathrm{C}}$ pre-mRNA editing that included a nonsignificant decrease of the ABCD-edited $\mathrm{mRNA}$ isoform and slightly decreased editing at the A, B, C, and D sites (Fig. $2 A, B$ ). This editing pattern is maintained in chronic fluoxetine-treated $\mathrm{C} 57 \mathrm{BL} / 6$ mice that are exposed to the FST (Fig. $2 A, B$ ). The $5-\mathrm{HT}_{2 \mathrm{C}}$ pre-mRNA editing pattern of fluoxetine-treated BALB/c mice, however, resembled that found for drug-naive mice subjected to the FST, but the magnitude of these changes is substantially larger and includes a highly significantly decreased expression of nonedited $5-\mathrm{HT}_{2 \mathrm{C}}$ mRNA (Fig. 2C,D). Despite the similar changes of $5-\mathrm{HT}_{2 \mathrm{C}}$ premRNA editing induced by either stress or chronic fluoxetine alone, chronic fluoxetine-treated $\mathrm{BALB} / \mathrm{c}$ mice exposed to the FST exhibited 5- $\mathrm{HT}_{2 \mathrm{C}}$ mRNA patterns that did not differ from drug-naive, nonstressed animals (Fig. 2C,D).

In summary, in C57BL/6 mice, neither stress nor chronic fluoxetine affect forebrain $5-\mathrm{HT}_{2 \mathrm{C}}$ pre-mRNA editing. In stressed and chronic fluoxetine-treated, nonstressed BALB/c mice, however, the percentage of edited mRNA encoding receptors with reduced constitutive activity and decreased agonist affinity and
C57B1/6
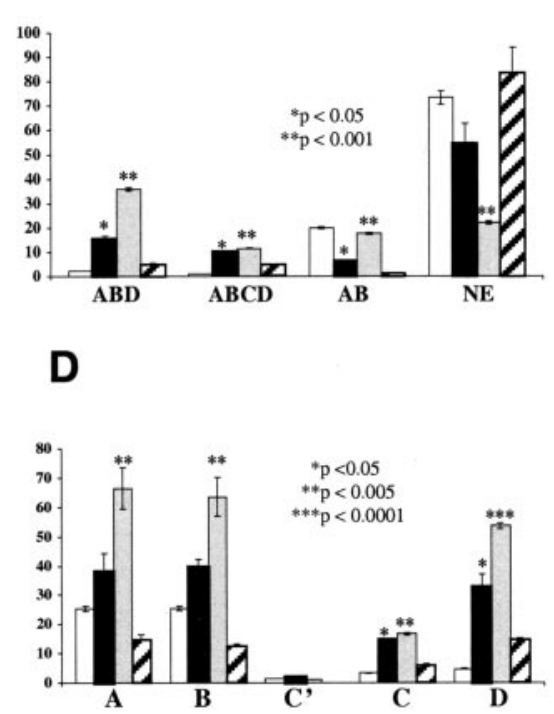

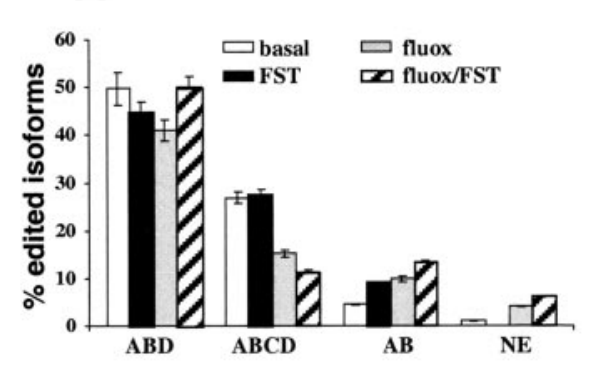

D
Balb/c

C
2. Percentages of major edited and nonedited (NE) $5-H_{2} \mathrm{mRNA}$ isoforms (top) and percentages of site-specific editing minimum of 48 sequences was obtained for each of the animals. Data were compared by one-way ANOVA, and statistical differences were resolved post hoc using the Tukey-Kramer multiple-comparison test.

potency is increased. However, when chronic fluoxetine treatment is combined with stress, the normal (baseline) editing pattern is maintained in these mice.

\section{Discussion}

The present study shows that two genetically different inbred strains of mice exhibit profoundly different forebrain neocortical $5-\mathrm{HT}_{2 \mathrm{C}}$ pre-mRNA editing patterns and different editing responses to stress and chronic fluoxetine treatment. Although the generally nonanxious and more stress-resistant C57BL/6 mice express mainly edited $5-\mathrm{HT}_{2 \mathrm{C}} \mathrm{mRNA}$ isoforms, $>70 \%$ of all $5-\mathrm{HT}_{2 \mathrm{C}}$ mRNA isoforms expressed in the forebrain neocortex of $\mathrm{BALB} / \mathrm{c}$ mice are nonedited and encode receptors with the highest constitutive activity and the highest sensitivity to serotonin. Moreover, although neither stress nor chronic fluoxetine treatment lead to significant alterations in $5-\mathrm{HT}_{2 \mathrm{C}}$ pre-mRNA editing in $\mathrm{C} 57 \mathrm{BL} / 6$ mice, both treatments increase editing in $\mathrm{BALB} / \mathrm{c}$ mice and result in increased expression of $5-\mathrm{HT}_{2 \mathrm{C}}$ mRNA encoding receptors with reduced constitutive activity and decreased agonist affinity and potency. However, when the FST is combined with chronic fluoxetine treatment, BALB/c mice exhibit a $5-\mathrm{HT}_{2 \mathrm{C}}$ pre-mRNA editing pattern that is indistinguishable from baseline.

The present study revealed different $5-\mathrm{HT}_{2 \mathrm{C}}$ pre-mRNA editing responses to chronic fluoxetine treatment in mice of different genetic backgrounds. We have shown previously that 129Sv mice treated chronically with fluoxetine exhibit significantly decreased $\mathrm{C}^{\prime}$-site editing, decreased C-site editing, and significantly increased D-site editing (Gurevich et al., 2002b). The data shown in Figure 2 show further that, although C57BL/6 mice treated with fluoxetine exhibit only very modest and nonsignificant reductions in A-, B-, C-, and D-site editing, editing of these sites is significantly increased in fluoxetine-treated BALB/c mice. This heightened response to chronic fluoxetine and the resultant in- 
crease in the synaptic concentration of serotonin, together with the low-baseline 5- $\mathrm{HT}_{2 \mathrm{C}}$ pre-mRNA editing that is likely to be an adaptive response to the low-baseline forebrain serotonin levels suggest that, compared with $\mathrm{C} 57 \mathrm{BL} / 6$ mice, the regulation of $5-\mathrm{HT}_{2 \mathrm{C}}$ pre-mRNA editing in $\mathrm{BALB} / \mathrm{c}$ mice is more sensitive to changes in the levels of serotonin. Moreover, the different editing responses to chronic fluoxetine detected in isogenic strains of mice with different genetic backgrounds support the idea that the (highly variable) antidepressant efficacy of fluoxetine is, at least in part, genetically determined.

Our study also shows that the $5-\mathrm{HT}_{2 \mathrm{C}}$ pre-mRNA editing response to stress differentiates stress-susceptible from lesssusceptible inbred strains. BALB/c mice are spontaneously anxious, and they are more reactive to stressors than C57BL/6 and 129Sv mice (Anisman et al., 1998; Dulawa et al., 2004). For example, Dulawa et al. (2004) showed that drug-naive BALB/c mice subjected to the same FST paradigm used in the present study spent less time swimming and more time passively floating compared with C57BL/6 mice and that chronic (but not acute) fluoxetine treatment significantly increased their (active) swimming time. As shown in the present study, the $5-\mathrm{HT}_{2 \mathrm{C}}$ pre-mRNA editing responses to the FST differ in these two strains of mice. In drug-naive and chronic fluoxetine-treated C57BL/6 mice, editing of $5-\mathrm{HT}_{2 \mathrm{C}}$ pre-mRNA is not significantly affected by FST treatment. Drug-naive BALB/c mice, however, exhibit an editing response to the FST that is qualitatively similar to their response to chronic fluoxetine, albeit less severe. It is conceivable that the strength of the stressor correlates directly with the magnitude of the $5-\mathrm{HT}_{2 \mathrm{C}}$ pre-mRNA editing response. Although the present study applied only a moderate and acute stressor, significant changes in $5-\mathrm{HT}_{2 \mathrm{C}}$ pre-mRNA editing are already evident, and it is likely that prolonged exposure to stress or more robust stressors increase further the magnitude of the editing response shown here.

An unexpected finding of the present study is that, in chronic fluoxetine-treated BALB/c mice that were exposed to the FST, the effect of fluoxetine on $5-\mathrm{HT}_{2 \mathrm{C}}$ pre-mRNA editing detected in nonstressed animals is abolished and that stress-induced editing changes are also no longer detectable. Hence, the $5-\mathrm{HT}_{2 \mathrm{C}}$ premRNA editing of these animals is indistinguishable from their corresponding baseline values. This finding points to the fact that the modulatory effects of chronic fluoxetine on $5-\mathrm{HT}_{2 \mathrm{C}}$ premRNA editing also depends on the behavioral state (stressed versus nonstressed) of the animal and that the therapeutic effects of fluoxetine are unmasked only in animals that show abnormal behavioral and $5-\mathrm{HT}_{2 \mathrm{C}}$ pre-mRNA editing responses to stress. Additional studies are needed to elucidate the molecular mechanism underlying this phenomenon.

Finally, it should be stressed that, in tests that rely on a bias toward passive behavior in previously stressed animals, the persistence of this passive behavioral strategy over active ones is thought to be characteristic of depression (learned helplessness) and susceptible to antidepressant treatment (Penza et al., 2003). Thus, the behavioral phenotypes of BALB/c mice, their uniquely low forebrain serotonin levels, and their responsiveness to chronic fluoxetine make this inbred strain more suitable for studies that aim at modeling depression than the C57BL/6 strain. Indeed, we found that acute stress applied to BALB/c mice elicits increased $5-\mathrm{HT}_{2 \mathrm{C}}$ pre-mRNA editing responses that lead to increased expression of mRNAs encoding receptors with decreased constitutive activity and decreased sensitivity to serotonin. Increased reactivity to stress also plays a significant role in major depression (Nemeroff and Owens, 2002; Nestler et al., 2002) and, similar to the stress-induced changes in $5-\mathrm{HT}_{2 \mathrm{C}}$ pre-mRNA editing in $\mathrm{BALB} / \mathrm{c}$ mice, changes in editing-site preferences found in the PFC of subjects with major depression also lead to a significantly increased expression of $5-\mathrm{HT}_{2 \mathrm{C}}$ mRNA isoforms encoding receptors with reduced ability to activate G-protein (Gurevich et al., 2002a). The stress-induced changes in editing-site preferences in mice and the changes in editing-site preferences in human subjects with major depression are species specific. This is evident from the basal expression of major edited isoforms in the human PFC [A(B)C'C sites-edited mRNA] and 129Sv or C57BL/6 forebrain neocortex (ABD and ABCD sites-edited mRNA). The major difference between both species is the editing preference of the $\mathrm{C}^{\prime}$ site, which is high in the human but very low in the mouse. This difference accounts for the fact that the major human edited mRNA isoform encoding receptors with the highest reduction of both constitutive activity and sensitivity to serotonin is edited at $\mathrm{A}(\mathrm{B}) \mathrm{C}^{\prime} \mathrm{C}$ sites and the corresponding mRNA in the mouse is ABCD sites edited (Gurevich et al., 2002a,b). However, both the stress-induced changes in editing and the changes in editing-site preferences detected in major depression lead to mRNA isoforms encoding receptors with decreased basal activity and decreased sensitivity to serotonin. These findings suggest that the altered 5 -HT-mediated regulation of $5-\mathrm{HT}_{2 \mathrm{C}}$ pre-mRNA editing in depression reflects a stress-related molecular response whose severity is possibly also genetically determined.

\section{References}

Anisman H, Zaharia MD, Meaney MJ, Merali Z (1998) Do early-life events alter behavioral and hormonal responses to stressors? Int J Dev Neurosci 16:149-164.

Belzung C, Griebel G (2001) Measuring normal and pathological anxietylike behaviors in mice: a review. Behav Brain Res 125:141-149.

Burns C, Chu H, Rueter SM, Hutchinson LK, Canton H, Sanders-Bush E, Emeson RB (1997) Regulation of serotonin-2C receptor G-protein coupling by RNA editing. Nature 387:303-308.

Dulawa SC, Holick KA Gundersen B, Hen R (2004) Effects of chronic fluoxetine in animal models of anxiety and depression. Neuropsychopharmacology 29:1321-1330.

Gurevich I, Tamir H, Arango V, Dwork AJ, Mann JJ, Schmauss C (2002a) Altered editing of serotonin $2 \mathrm{C}$ receptor pre-mRNA in the prefrontal cortex of depressed suicide victims. Neuron 34:349-356.

Gurevich I, Englander MT, Adlersberg M, Siegal N, Schmauss C (2002b) Modulation of serotonin $2 \mathrm{C}$ receptor editing by sustained changes in serotonergic neurotransmission. J Neurosci 22:10529-10532.

Nemeroff CB, Owens MJ (2002) Treatment of mood disorders. Nat Neurosci [Suppl] 5:1068-1070.

Nestler EJ, Barrot M, DiLeone RJ, Eisch AJ, Gold SJ, Monteggia LM (2002) Neurobiology of depression. Neuron 34:13-25.

Niswender C, Copeland SC, Herrik-Davis K, Emeson RB, Sanders-Bush E (1999) RNA editing of the human serotonin 5-hydroxytryptamine 2C receptor silences constitutive activity. J Biol Chem 274:9472-9478.

Penza KM, Heim C, Nemeroff CB (2003) Neurobiological effects of childhood abuse: implications for the pathophysiology of depression and anxiety. Arch Women Ment Health 6:15-22.

Porsolt RD, Bertin A, Jalfre M (1977) Behavioral despair in mice: a primary screening test for antidepressants. Arch Int Pharmacodyn Ther 229:327-336.

Tang X, Orchard SM, Sanford LD (2002) Home cage activity and behavioral performance in inbred and hybrid mice. Behav Brain Res 136:555-569.

Wang Q, O'Brien P, Chen C-X, Cho D-SC, Murray JM, Nishikura K (2000) Altered $\mathrm{G}$ protein-coupling functions of RNA editing isoform and splicing variant serotonin $2 \mathrm{C}$ receptors. J Neurochem 74:1290-1300.

Zhang X, Beaulieu J-M, Sotnikova TD, Gainetdinov RR, Caron MG (2004) Tryptophan hydroxylase-2 controls brain serotonin synthesis. Science 305:217. 